\title{
The Ability of Synoviocytes to Support Terminal Differentiation of Activated B Cells May Explain Plasma Cell Accumulation in Rheumatoid Synovium
}

\author{
Julie Dechanet, Pierre Merville, Isabelle Durand, Jacques Banchereau, and Pierre Miossec* \\ Schering-Plough Laboratory for Immunological Research, 69571 Dardilly, France; and *Departments of Immunology and \\ Rheumatology, INSERM U80, Hôpital Edouard Herriot, 69437 Lyon, France
}

\begin{abstract}
To understand the accumulation of plasma cells within RA synovium, the ability of rheumatoid synoviocytes to support the differentiation of $B$ cells into plasma cells was explored. Tonsillar B lymphocytes cultured over confluent monolayers of synoviocytes, secreted threefold more Igs (mainly IgM) than B cells cultured directly on plastic well. More importantly, synoviocytes enhanced by 14-fold the production of Igs (mainly IgG) by B cells costimulated with Staphylococcus aureus Cowan (SAC) particles. IL-10 and, in a lower extent, IL-2 increased Ig secretion in cocultures, and their combination was synergistic. In the presence of SAC, IL-2, and IL-10, synoviocytes increased by 13-884-fold the production of IgG, which reached $0.19 \mathrm{ng} /$ cell per day. RA as well as normal synoviocytes were more potent than other adherent cell lines to support terminal $B$ cell differentiation. Synoviocyte activity involved both a support of B cell survival, and an induction of the terminal differentiation of $B$ cells into mature plasma cells with typical morphology, high levels of intracytoplasmic Igs, and $\mathrm{CD20}^{-} \mathrm{CD38}^{\text {high }}$ surface expression. The present observation should permit the identification of molecules involved in the maturation of $B$ cells into plasma cells, and in their accumulation in rheumatoid synovium. (J. Clin. Invest. 1995. 95:456-463.) Key words: rheumatoid arthritis - B lymphocyte differentiation - cytokines - synoviocytes $\cdot$ plasma cells
\end{abstract}

\section{Introduction}

The ultimate role of B lymphocytes is to produce Igs, what necessitates their differentiation into plasma cells, as a result of a complex cascade of events which requires precise and coordinated regulation (1-3). After antigen binding, naive $B$ cells proliferate in a $\mathrm{T}$ cell-dependent fashion within the paracortical $\mathrm{T}$ cell-rich areas of secondary lymphoid organs. Then, a proportion of proliferating B cells mature into plasma blasts that will migrate to medullary cords to become plasma cells, while some B cells migrate into primary follicles to initiate the germinal center reaction. Germinal centers allow the generation of memory B cells and plasma blasts which have the potential of secreting antibodies of high affinity and high specificity. These plasma blasts migrate out of the follicles to colonize

Address correspondence to J. Dechanet, Schering-Plough Laboratory for Immunological Research, 27, chemin des Peupliers, B.P. 11, 69571 Dardilly Cedex, France. Phone: 72-17-27-00; FAX: 78-35-47-50.

Received for publication 24 August 1994.

J. Clin. Invest.

(c) The American Society for Clinical Investigation, Inc.

0021-9738/95/02/0456/08 $\$ 2.00$

Volume 95, February 1995, 456-463 either the mucosal lamina propria, or the bone marrow $(4,5)$ where they terminally differentiate into high-rate Ig secreting plasma cells.

In some pathological circumstances, plasma cells are also found in ectopic sites. Indeed in RA, an accumulation of plasma cells has been demonstrated among the mononuclear cells infiltrating the synovium of affected joints $(6-8)$. The inflammatory synovial tissue was shown to share with normal lymphoid organs, structural and functional properties, including B cell and $\mathrm{T}$ cell-rich areas, the presence of dendritic cells and plasma cells, and an important Ig production $(9,10)$. In RA synovitis, plasma cells are organized in clusters located in the transitional areas in close contact with macrophages, synoviocytes and blastic $\mathrm{CD}^{+} \mathrm{T}$ cells, at the margin of the lymphocyte rich area mainly composed of small $\mathrm{CD}^{+}{ }^{+} \mathrm{T}$ cells aggregated around post-capillary venules with tall endothelium (11). The mechanisms through which plasma cells accumulate in the synovium have not yet been explored. Therefore, we engaged into the study of the role of synovium microenvironment in B cell differentiation. To mimic in vitro the ectopic development of plasma cells, we assessed the capacity of purified rheumatoid synoviocyte cultures (12), to support the differentiation of activated B lymphocytes into plasma cells.

Here, we show that purified B lymphocytes cocultured on synoviocyte monolayers can spontaneously secrete microgram amounts of Igs. Further addition to these cocultures of Staphylococcus aureus Cowan (SAC) ${ }^{1}$ particles and a combination of IL-2 and IL-10, results in the generation of high rate IgGsecreting non proliferating plasma cells.

\section{Methods}

Cytokines and cell lines. Each of the recombinant human cytokines from the following sources were used at the following concentrations, known to be saturating in various biological assays. IL-1 $\beta(1 \mathrm{ng} / \mathrm{ml})$, IL-6 (40 $\mathrm{ng} / \mathrm{ml})$, and TNF- $\alpha(20 \mathrm{ng} / \mathrm{ml})$ from Genzyme (Boston, MA); IL2 (10 $\mathrm{ng} / \mathrm{ml})$ and IFN- $\gamma(10 \mathrm{ng} / \mathrm{ml})$ from Amgen Biologicals (Thousands Oaks, CA); IL-3 (15 ng/ml), GM-CSF (100 ng/ml), IL-4 (5 ng/ml), and IL$10(50 \mathrm{ng} / \mathrm{ml})$ from the Schering-Plough Research Institute (Kenilworth, NJ); IL-7 (10 ng/ml) from R \& D Systems Inc. (Minneapolis, MN); TGF- $\beta(1 \mathrm{ng} / \mathrm{ml})$ from Oncomembrane Inc. (Seattle, WA). IL-5, semipurified by affinity column chromatography from culture supernatants of COS 7 cells transfected with the IL-5 cDNA, was kindly provided by Dr. R. Coffman (DNAX, Palo Alto, CA) and was used at $50 \mathrm{ng} / \mathrm{ml}$.

HeLa cell line, SV-40-transformed human bone marrow stroma cell line (Cole) and human lung fibroblast line (MRC5) were purchased from American Type Culture Collection (Rockville, MD).

Antibodies. The monoclonal mouse antibodies used for the phenotypic studies were purchased from the following sources: FITC-conjugated anti-CD3 (IOT3), anti-CD19 (IOB4), anti-CD20 (IOB20), and anti-CD54 (ICAM-1) from Immunotech (Marseille, France); FITC-con-

1. Abbreviation used in this paper: SAC, Staphylococcus aureus strain Cowan. 
jugated anti-CD10 (Calla), anti-CD14 (Leu M3), anti-HLA-DR, phycoerythrin-conjugated anti-CD38 (Leu 17) from Becton Dickinson Monoclonal Center (Mountain View, CA); FITC-conjugated anti-CD44 (A3D8) from Sigma Chemical Co. (St. Louis, MO); and FITC-conjugated anti-CD28 from CLB (Amsterdam, The Netherlands). The antiCD40 mAb 89 was produced in the laboratory as described previously (13). The mouse anti- $\kappa$ and anti- $\lambda$ antibodies used for the immunoenzymatic staining were from Dako (Glostrup, Denmark). The anti-CD2 and anti-CD3 mAbs used for the negative selection of B cells with magnetic beads were purchased from Aster Laboratories (La Gaude, France).

Synoviocyte preparation. RA synoviocytes were isolated from synovial biopsies obtained from RA patients undergoing knee or wrist synovectomy. Normal synoviocytes were obtained from patients undergoing knee arthroscopy for traumatic ligament lesions. Synovia were finely minced and digested with $4 \mathrm{mg} / \mathrm{ml}$ collagenase (Worthington Biochem. Corp., Freehod, NJ) for $2-3 \mathrm{~h}$ at $37^{\circ} \mathrm{C}$. After centrifugation, cells were resuspended in complete $\alpha$-MEM medium as detailed elsewhere (12). After $48 \mathrm{~h}$, non-adherent cells were removed. Adherent cells were cultured in complete medium, and at confluence were passaged in a 1:3 ratio after trypsin treatment. Synoviocytes were used between passages 3 and 8 . They were a homogenous population of fibroblast-like cells, negative for the expression of CD3, CD19, CD14, and HLA-DR, and positive for the expression of CD44, CD10, and CD54, as determined by flow cytometry analysis.

B lymphocyte purification. Tonsillar mononuclear cells were separated by standard Ficoll-Hypaque gradient method and were submitted to rosetting with sheep red blood cells. Nonrosetting cells were next labeled with anti-CD2 and anti-CD3 mAbs, and subsequently incubated with magnetic beads coated with anti-mouse IgG antibodies (Dynal, Oslo, Norway). Residual non B cells were removed by applying a magnetic field. The purity of B cell population was routinely $>95 \%$, as estimated by flow cytometry analysis using anti-CD19, CD20, CD3, and CD14 mAbs.

SAC blast preparation. SAC blasts were prepared as previously described (14). Briefly, purified tonsillar B cells at $2 \times 10^{6} \mathrm{cells} / \mathrm{ml}$ in RPMI 1640 medium (GIBCO BRL, Grand Island, NY) supplemented with $10 \%$ FCS (GIBCO BRL), $2 \mathrm{mM}$ glutamine, $100 \mathrm{U} / \mathrm{ml}$ penicillin, and $100 \mu \mathrm{g} / \mathrm{ml}$ streptomycin (all from Flow Laboratories, Mc Lean, VA), were stimulated for $48 \mathrm{~h}$ with formalinized particles of SAC (Calbiochem-Behring Corp., La Jolla, CA) used at a final concentration of $0.05 \%$. To remove non viable cells and SAC particles, activated B cells were centrifuged $(15 \mathrm{~min}, 550 \mathrm{~g})$ on a gradient consisting of two overlaid solutions of Ficoll $(d=1.077 \mathrm{~g} / \mathrm{ml})$ and Percoll $(d=1.055 \mathrm{~g} /$ $\mathrm{ml})$. Viable B cell blasts were recovered at the interface between the two solutions.

Cocultures of synoviocytes and B cells. $7 \times 10^{3}$ synoviocytes/well were seeded in flat-bottomed 96-well culture plates and allowed to reach confluence for 24 to $72 \mathrm{~h}$. After irradiation (5,500 rad) and washing directly in the plates, 1 to $5 \times 10^{4}$ purified resting B cells or SAC blasts were added. Cocultures were performed in $200 \mu \mathrm{l} /$ well of Iscove's medium (Flow Laboratories, Irvine, CA) enriched with $50 \mu \mathrm{g} / \mathrm{ml}$ human transferrin, $0.5 \%$ BSA, $5 \mathrm{mg} / \mathrm{ml}$ bovine insulin (all from Sigma Chemical Co.), 10\% heat-inactivated FCS (GIBCO BRL), $2 \mathrm{mM}$ glutamine, $100 \mathrm{U} / \mathrm{ml}$ penicillin and $100 \mu \mathrm{g} / \mathrm{ml}$ streptomycin (all from Flow Laboratories). Cytokines or SAC were added at the onset of the coculture.

IgG, IgM, and IgA levels were determined in supernatants by standard ELISA techniques, as described earlier (14). For viable B cell recovery, all cells including adherent as well as non adherent populations, were harvested after trypsin treatment. B cells, easily distinguishable from synoviocytes by size, were counted by trypan blue dye exclusion.

Flow cytometric analysis. For phenotypic analysis, $5 \times 10^{5} \mathrm{~B}$ cells were cocultured on a confluent monolayer of synoviocytes $\left(\sim 5 \times 10^{4}\right.$ cells). After the indicated culture duration, cells were harvested by extensive washing, without trypsin treatment. Single and double-color cell-surface fluorescence was performed according to standard direct immunofluorescence techniques as previously described (15), using isotype-matched unrelated murine mAbs as negative controls. Fluorescence was analyzed on a FACScan ${ }^{\circledR}$ flow cytometer (Becton Dickinson, Sun-

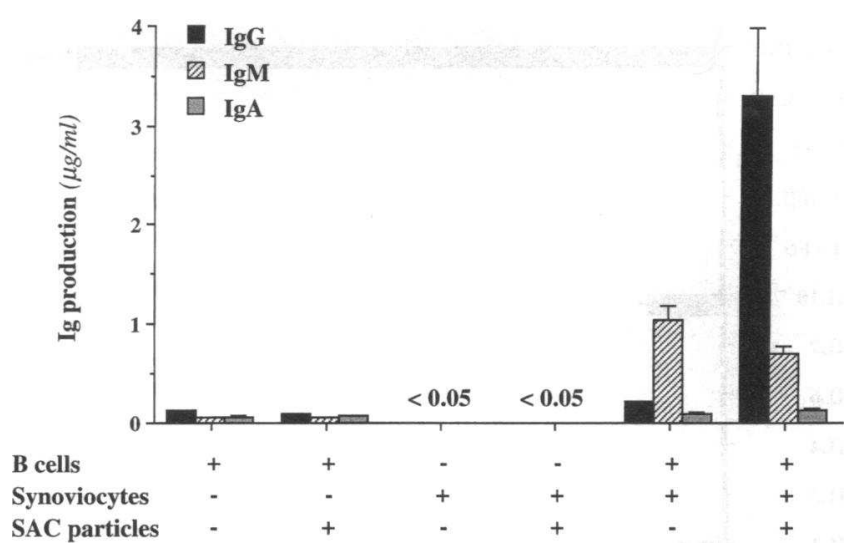

Figure 1. Rheumatoid synoviocytes sustain Ig production by resting or SAC activated B cells. $5 \times 10^{4}$ resting B cells were cultured for $10 \mathrm{~d}$ either directly on plastic well or over a confluent monolayer of irradiated synoviocytes. Confluent cultures of irradiated synoviocytes without B cells were also tested. All cultures were performed in the presence or absence of SAC $(0.05 \%)$. Ig levels in supernatants were measured by ELISA. Results are expressed as mean \pm SD of culture triplicates. Representative of six experiments.

nyvale, CA). Gating was set according to forward and wide-angle light scatter parameters to exclude synoviocytes and subcellular particles from acquisition data. Data were subsequently processed using the Lysis program (Becton Dickinson).

Immunoenzymatic staining: All cells from cocultures were harvested by extensive washing, cytospun and fixed in cold acetone for $5 \mathrm{~min}$, washed in PBS and incubated with anti- $\kappa$ and anti- $\lambda$ mAbs diluted $1 / 40$ in PBS or with an isotype matched non related mAb. Binding was revealed using sheep anti-mouse IgGAM antibody (The Binding Site, Birmingham, UK) and soluble complexes of alkaline phosphatase and anti-phosphatase mAb (Dako, Glostrup, Denmark). Substrate was Fast Red TR salt (Dako) which yielded a red precipitate.

Statistical analysis. Each figure shows one representative experiment where data are expressed as mean $\pm \mathrm{SD}$ of culture triplicates. When results from various separated experiments are pooled, results indicated in the text are expressed as mean \pm SEM of indicated number of experiments $(n)$. Differences between different groups were compared for significance with the Wilcoxon nonparametric T-test.

\section{Results}

Rheumatoid synoviocytes are able to induce human B lymphocytes to secrete important levels of Igs. To assess the role of synovium microenvironment in B lymphocyte differentiation, we studied the interaction between human B cells and synoviocytes. Thus, coculture assays were performed with purified tonsillar B cells seeded on a confluent monolayer of irradiated rheumatoid synoviocytes. SAC particles were added to some cultures in order to activate B lymphocytes in a polyclonal fashion. The differentiation of B cells was tested by measuring the production of Igs in the supernatants after $10 \mathrm{~d}$ of coculture.

As shown in Fig. 1, $5 \times 10^{4} \mathrm{~B}$ cells cultured directly on culture vessel (plastic) in medium alone produced low amounts of Igs which were not increased by addition of SAC. In contrast, when the same numbers of B cells were cultured on a confluent monolayer of synoviocytes, spontaneous total Ig production was enhanced. The mean \pm SEM production of total Igs (IgM + IgG $+\operatorname{IgA}$ ) from six separate experiments was: $787 \pm 181 \mathrm{ng} / \mathrm{ml}$ over synoviocytes vs. $242 \pm 20$ on plastic $(P<0.03)$. Secreted Igs were predominantly of the IgM isotype. The enhancing 


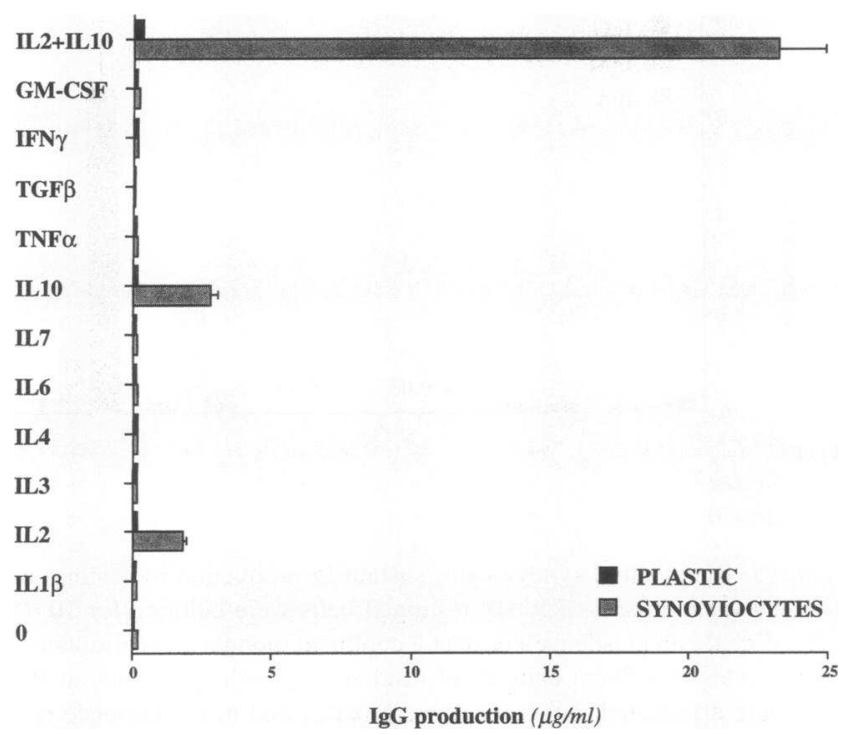

Figure 2. Response to cytokines of B cells cultured over synoviocytes. $1 \times 10^{4}$ resting B cells were cultured for 10 days either directly on plastic (black bars) or on a confluent monolayer of irradiated synoviocytes (shaded bars). Cocultures were performed in the presence of SAC $(0.05 \%)$, and with or without recombinant cytokines used at the concentrations indicated in Methods. IgG levels were measured by ELISA. Results are expressed as mean \pm SD of culture triplicates. Representative of 14 experiments for $0, \mathrm{IL}-2, \mathrm{IL}-10$, and IL-2 + IL-10, and four experiments for the other cytokines.

effect of synoviocytes on total Ig production was even more important when B cells were costimulated with SAC $(3105 \pm 930 \mathrm{ng} / \mathrm{ml}$ over synoviocytes vs. $210 \pm 34$ on plastic, $n$ $=6, P<0.03$ ), and IgG was the major isotype produced under these conditions. IgA synthesis was poorly affected by culturing tonsillar B cells over synoviocytes. No detectable Ig was found in synoviocyte supernatant, confirming the absence of residual B cells within synoviocyte preparations. The capacity of synoviocytes to induce $B$ cells to secrete Igs was dependent on their density in the coculture. The maximal Ig production was obtained when $B$ cells were cultured over $1 \times 10^{4}$ synoviocytes per well which corresponds to a confluent monolayer of synoviocytes (data not shown). When B cells were preactivated with SAC for $48 \mathrm{~h}$ (SAC Blasts), instead of coactivated with SAC as presented in Fig. 1, and then cocultured with synoviocytes in medium alone, synoviocytes also stimulated Ig production with a large predominance of IgG (data not shown).

IL-2 and IL-10 strongly increase Ig secretion by $B$ lymphocytes cocultured with synoviocytes. As several cytokines have been shown to induce B cell growth and differentiation (2), we examined whether they could enhance the production of Igs by B cells cocultured with synoviocytes. 1 X $10^{4} \mathrm{~B}$ cells were cultured for $10 \mathrm{~d}$ either directly on plastic or over a confluent monolayer of synoviocytes, and eleven different purified recombinant cytokines (IL-1 $\beta$, IL-2, IL-3, IL-4, IL-6, IL-7, IL-10, TNF- $\alpha$, TGF- $\beta$, IFN- $\gamma$, and GM-CSF) were tested for their ability to increase IgG production in the presence of SAC.

As illustrated in Fig. 2, all tested cytokines were unable to induce purified $B$ cells to secrete IgG in the absence of a synoviocyte layer (black bars). When B cells were cocultured over synoviocytes (shaded bars), IL-10 and to a lower extent IL-2, were the only cytokines able to enhance the production of IgG. Thus, SAC activated B cells cultured with synoviocytes and either IL-2 or IL-10 produced micrograms amounts of IgG per milliliter. Moreover, when $\mathrm{IL}-2$ and $\mathrm{IL}-10$ were used in combination a strong synergistic effect was observed, and the own effect of synoviocytes was dramatic since they enhanced by $13-884$-fold the production of IgG $(2.0 \pm 1.4 \mu \mathrm{g} / \mathrm{ml}$ without vs. $62.5 \pm 19.0 \mu \mathrm{g} / \mathrm{ml}$ with synoviocytes, $n=14, P<0.001)$. In the same supernatants, IgM levels were similarly affected by the cytokines but they were lower than those of IgG in each condition (data not shown). IL-5 was also tested in the same culture conditions and showed no effect on IgG, M and A production (data not shown).

The synergy between IL-2 and IL-10 on IgG production by $B$ cells cocultured with synoviocytes and SAC was dose dependent (Fig. 3, $A$ and $B$ ). The maximal effect was obtained with $10-20 \mathrm{U} / \mathrm{ml}$ of IL-2 associated with $30-50 \mathrm{ng} / \mathrm{ml}$ of IL10. Kinetic studies showed that IgG production by B cells cultured over synoviocytes started at day 6 (Fig. $3 \mathrm{C}$ ). The inducing effect of IL-2 alone was modest with a maximum reached at around day 10. In contrast, the secretion of IgG enhanced by IL-10 alone increased up to day 19, and levels of secreted IgG were then ten fold higher than those reached with $I L-2$. The sustained synergy between IL-2 and IL-10 over time, induced the production of hundreds of micrograms of IgG per milliliter at the end of the culture. In four distinct experiments, mean \pm SEM levels of Igs detected during the third week of culture were: $177 \pm 44 \mu \mathrm{g} / \mathrm{ml}$ of IgG (range: $81-321$ ), $98 \pm 54$ $\mu \mathrm{g} / \mathrm{ml}$ of IgM (range: $4-269$ ) and $19 \pm 9 \mu \mathrm{g} / \mathrm{ml}$ of IgA (range: 3-48). These astonishingly high levels of Igs were not due to technical flaws in our ELISA assays which calibration had been rigorously checked. The mean distribution of IgG subclasses in cocultures of B cells with synoviocytes in the presence of SAC were $85 \%$ of IgG1, $15 \%$ of IgG2, 1\% of IgG3, and 1\% of IgG4 (data not shown). Addition of IL-2 and/or IL-10 did not affect the relative percentages of IgG subclasses.

Normal and RA synoviocytes are more potent than other adherent cell lines to support Ig production by $B$ cells. To know whether the ability of synoviocytes to sustain Ig production by B cells was related to their rheumatoid origin, normal synoviocytes, from three patients undergoing arthroscopy for traumatic ligament lesions, were tested in the same conditions as rheumatoid synoviocytes. Results presented in Table I indicate that normal synoviocytes were as potent as rheumatoid cells to induce IgG production by B cells cultured in the presence of SAC. Similar synergy between IL-2 and IL-10, and similar quantities of IgG were obtained with normal and RA synoviocytes.

In view of the above findings, we investigated whether the ability of synoviocytes to induce Ig production by SAC activated $B$ cells was shared by other adherent cell lines. With this aim, B cells were cultured with SAC, IL-2, and IL-10 without or with human carcinoma cells (HeLa), SV-40 transformed human bone marrow stroma (Cole) and human lung fibroblasts (MRC5). Synoviocytes from four different patients were tested in parallel. As presented in Fig. 4, B cells cocultured on a confluent monolayer of each of the adherent cell lines produced higher levels of IgG than those cultured directly on plastic. However, none of these cell lines were as potent as each of the synoviocyte culture tested to induce IgG secretion. Indeed, in 7 separate experiments IgG levels obtained with synoviocytes were $9.3 \pm 2.6$-fold higher (range: $2.8-24.5, P<0.02$ ) than those reached with MRC5 cells.

$B$ lymphocytes cultured over synoviocytes terminally differentiate into plasma cells. Morphology and phenotype of the B cells were analyzed to determine the ability of synoviocytes to 

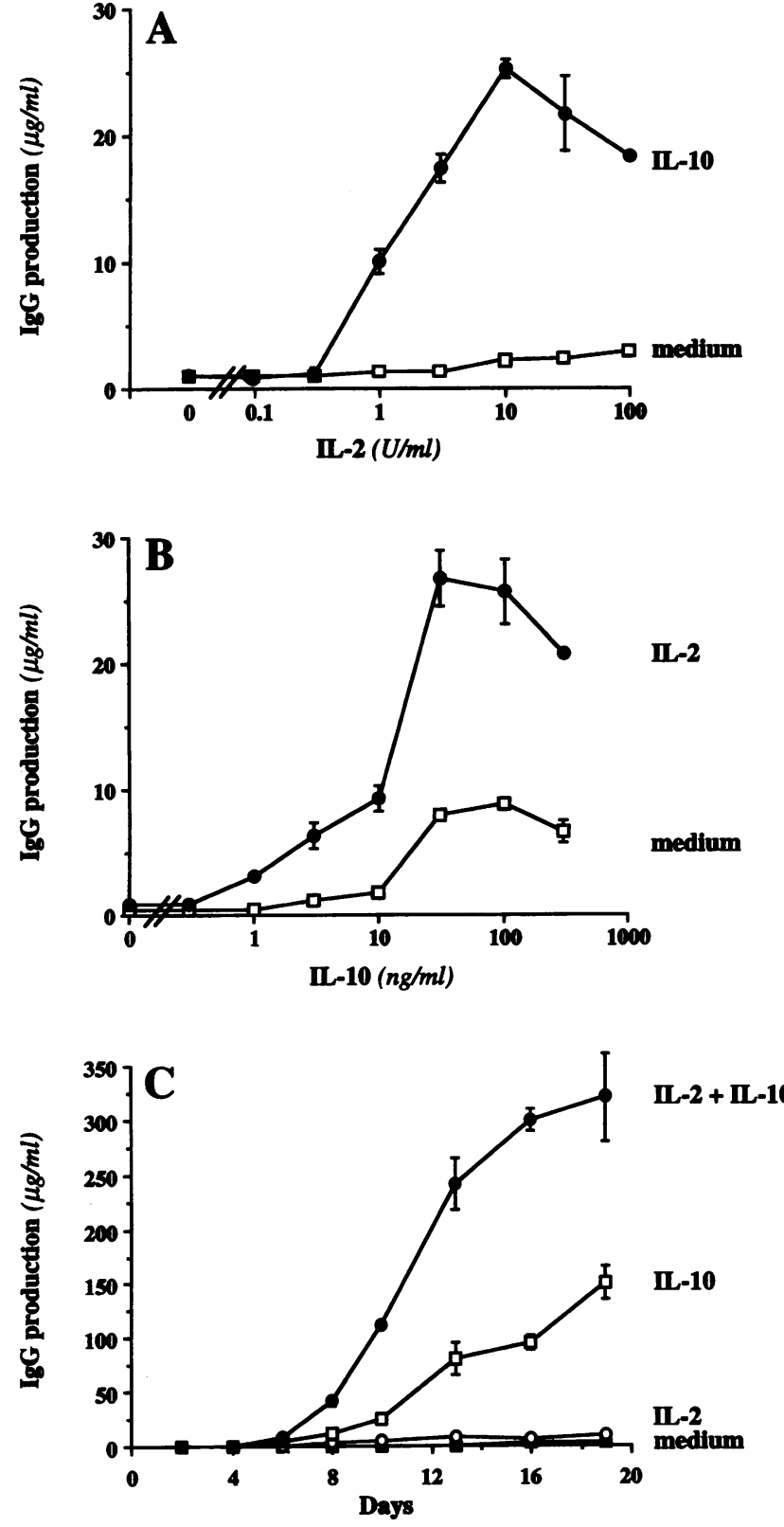

Figure 3. IL-2 and IL-10 synergize for the production of Igs by B cells cultured over synoviocytes. $1 \times 10^{4}$ resting B cells were cultured over a confluent monolayer of irradiated synoviocytes in the presence of SAC $(0.05 \%)$. (A) Serial dilutions of IL-2 were added with or without IL-10 $(50 \mathrm{ng} / \mathrm{ml})$ and $\mathrm{IgG}$ levels were measured at day 10. (B) Serial dilutions of IL-10 were added with or without IL-2 $(10 \mathrm{ng} / \mathrm{ml})$ and IgG levels were measured at day 10 . (C) IL-2 $(10 \mathrm{ng} / \mathrm{ml}), I L-10(50 \mathrm{ng} / \mathrm{ml})$ or a combination of both were added to the cocultures, and IgG production was measured every second or third day. Results are expressed as mean \pm SD of culture triplicates. Representative of two experiments.

induce terminal differentiation of B cells into plasma cells. When SAC blasts were cocultured with synoviocytes in the presence of $\mathrm{IL}-2$ and $\mathrm{IL}-10$, examination of cultures under phase-contrast microscopy revealed foci of large refringent spherical B cells in close contact with the adherent layer of synoviocytes (Fig. $5 \mathrm{~A}$ ). When cells were harvested, cytospun and stained with Giemsa dye, most of the B cells showed a typical plasma cell morphology, with an intensely basophilic
Table I. Normal Synoviocytes Are as Potent as RA Synoviocytes to Induce IgG Production by B Cells

\begin{tabular}{lrrrr}
\hline & \multicolumn{5}{c}{ IgG production } \\
\cline { 2 - 5 } & - & IL2 & IL10 & IL2 + IL10 \\
\hline \multicolumn{5}{c}{ Mg/ml } \\
Exp. 1 & \multicolumn{5}{c}{. 0.1} & 0.1 & 1.8 & 3.4 \\
Plastic & 0.3 & 3.9 & 6.4 & 31.3 \\
PR 1 & 0.2 & 1.8 & 7.9 & 30.0 \\
N 1 & 1.8 & 4.6 & 9.5 & 56.1 \\
N 2 & & & & \\
Exp. 2 & 0.3 & 0.3 & 0.4 & 0.5 \\
Plastic & 0.7 & 5.4 & 7.7 & 65.9 \\
PR 2 & 0.7 & 7.4 & 3.3 & 46.7 \\
N 3 & & &
\end{tabular}

$1 \times 10^{4}$ resting B cells were cultured for $10 \mathrm{~d}$ in the presence of SAC $(0.05 \%)$, either on plastic or on a confluent monolayer of irradiated synoviocytes from two rheumatoid patients (PR 1,2) or from three normal individuals (N 1 to 3 ). Cocultures were performed with or without IL2 $(10 \mathrm{ng} / \mathrm{ml})$ and/or IL10 $(50 \mathrm{ng} / \mathrm{ml})$. IgG levels were measured by ELISA and expressed as mean of culture triplicates. SD never exceeded $10 \%$ of the mean value.

cytoplasm, an eccentric nucleus and a light archoplasm (Fig. 5 $B)$. Immunoenzymatic staining with anti- $\kappa$ and anti- $\lambda$ antibodies demonstrated that these cells strongly expressed intracytoplasmic Igs (Fig. 5 C).

Bone marrow plasma cells, when compared to mature B cells, are characterized by an overexpression of the surface antigen CD38 and the loss of CD20 (16). Thus, expression

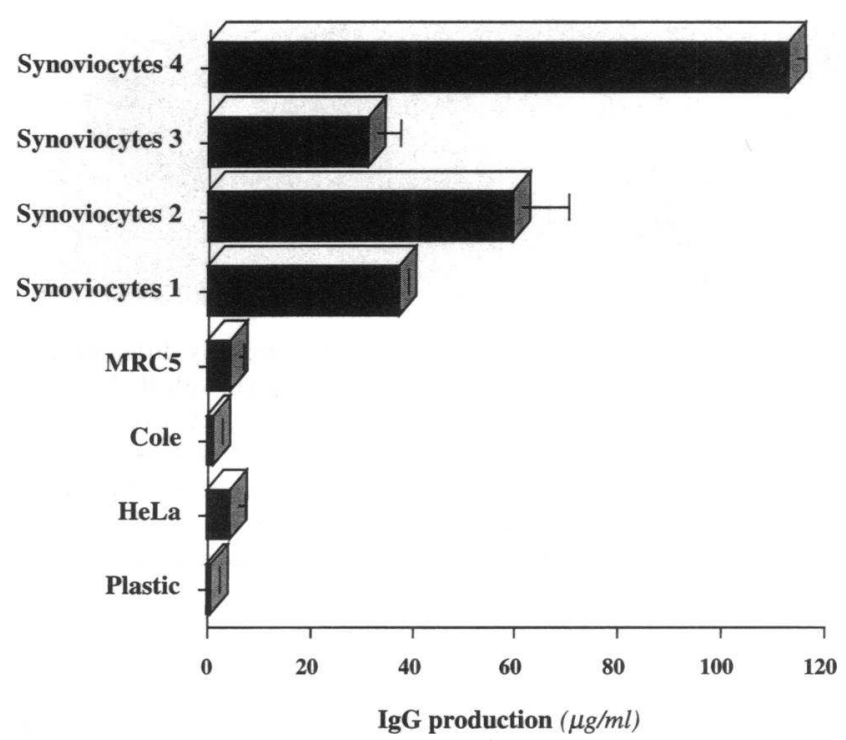

Figure 4. RA synoviocytes are more potent than other adherent cell lines to support Ig production by B cells. $1 \times 10^{4}$ resting B cells were cultured over a confluent monolayer of different irradiated fibroblastlike cell lines (MRC5, Cole, HeLa) or synoviocytes from four different patients (1 to 4$)$, in the presence of SAC $(0.05 \%), \mathrm{IL}-2(10 \mathrm{ng} / \mathrm{ml})$, and IL-10 $(50 \mathrm{ng} / \mathrm{ml})$. IgG production was measured at day 10 by ELISA. Results are expressed as mean \pm SD of culture triplicates. Representative of four experiments. 


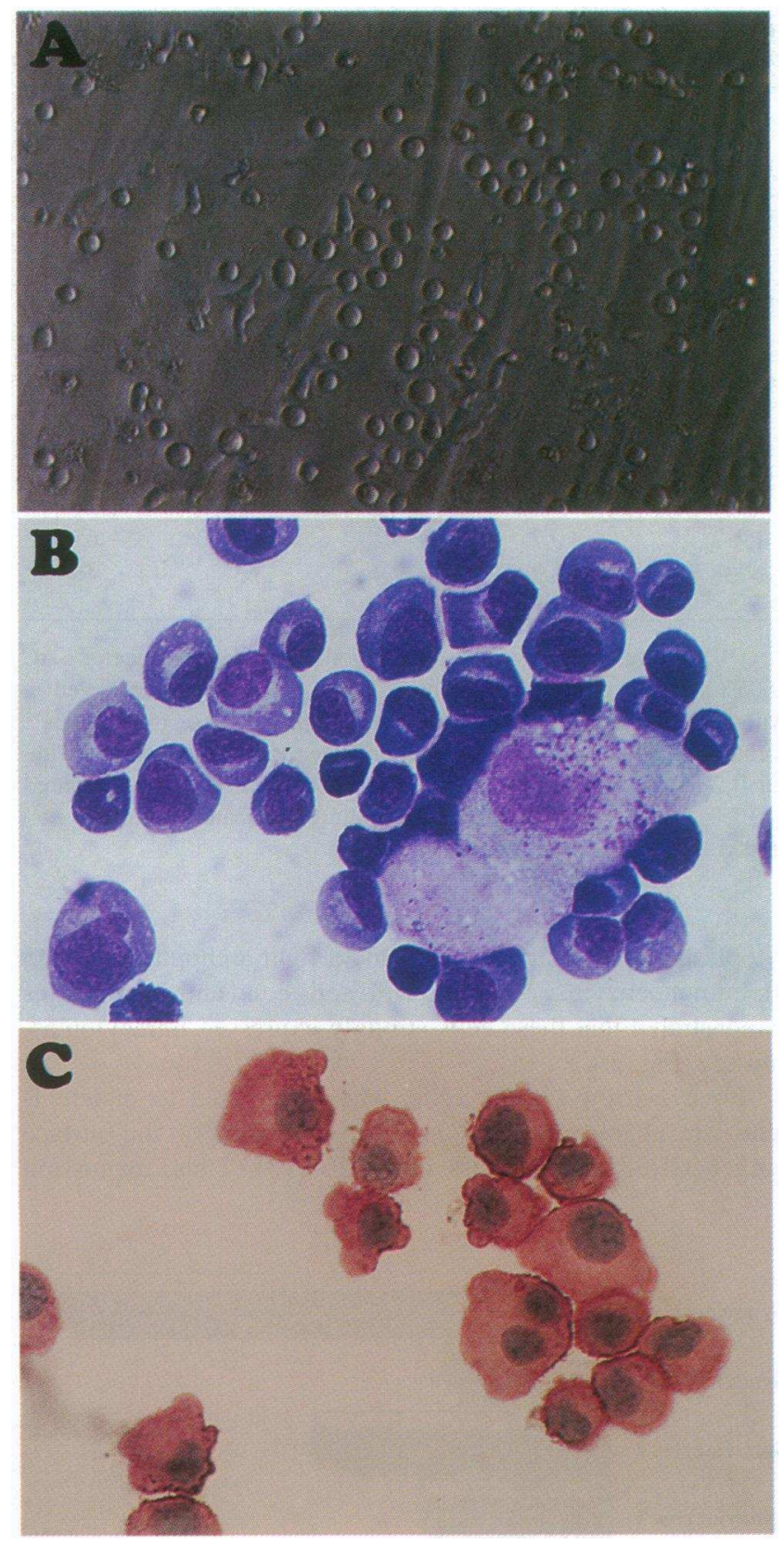

Figure 5. B cells cocultured on synoviocytes terminally differentiate into plasma cells. $1 \times 10^{4} \mathrm{SAC}$ blasts were cultured with IL-2 (10 ng/ $\mathrm{ml})$ and $\mathrm{IL}-10(50 \mathrm{ng} / \mathrm{ml})$ over synoviocytes for $7 \mathrm{~d}$. (A) Coculture examination under phase contrast microscopy $(\times 120)$. $(B)$ Giemsa staining of harvested cells showing one synoviocyte surrounded by plasma cells $(\times 600)$. (C) Immunoenzymatic staining with anti- $\kappa$ and anti- $\lambda$ antibodies yielding red precipitate, followed by a second staining with hematoxylin $(\times 600)$.

of these antigens on B cells before and during coculture with synoviocytes was analyzed by flow cytometry. Gating according to cell size and granulosity allowed separation of synoviocytes from B cells. The presence of possibly contaminating CD $38^{+}$ $\mathrm{T}$ cells was ruled out by staining with anti-CD3 mAbs. Dot plot presented in Fig. $6 \mathrm{~A}$ showed that all freshly isolated tonsillar B cells expressed CD20. A subpopulation (52\% for this sample) expressed CD38 at intermediate intensity, characterizing germinal center cells (17). After $48 \mathrm{~h}$ of activation with SAC (Fig. 6
$B$ ), the number of $\mathrm{CD} 38^{+}$cells slightly increased (77\% of cells), while the number of $\mathrm{CD} 20^{+}$cells was not affected. In contrast, after one week of subsequent coculture with synoviocytes, IL2 and IL-10 (Fig. $6 \mathrm{C}$ ), an important cell population lacking surface CD20 and expressing CD38 with high intensity was observed. When cocultures were performed for a total of $2 \mathrm{wk}$ (Fig. $6 \mathrm{D}$ ), this $\mathrm{CD}^{-} 0^{-} \mathrm{CD} 38^{\text {high }}$ population represented the majority of the cells. The double negative population recovered in Fig. 6, $C$ and $D$ represented residual synoviocytes. Further phenotyping of the CD20- $\mathrm{CD} 38^{\text {high }}$ cells obtained in Fig. $6 \mathrm{D}$ revealed their homogenous expression of surface CD19 and CD40 as on resting B cells (Fig. 7). All these cells were also $\mathrm{CD}_{4}{ }^{+}$and $\mathrm{CD}^{-} 0^{-}$as described for normal bone marrow plasma cells (16). CD28 which had been observed on plasmacytoma cell lines (18) was not expressed on these cells.

Synoviocytes promote B cell survival while stimulating their terminal differentiation toward high rate Ig-secreting plasma cells. We wondered whether the activity of synoviocytes to sustain B cell differentiation was related to an induction of B cell proliferation. SAC blasts were used to separate B cell growth due to SAC from that induced by synoviocytes. SAC Blasts were cultured either on plastic, MRC5 or synoviocytes, with IL-2 and IL-10. Viable B cell recovery was measured every third day in parallel with IgG levels. As shown in Fig. 8 $A, \mathrm{~B}$ cells cultured on plastic poorly survived, as indicated by the rapid fall of viable $B$ cell number over $12 \mathrm{~d}$ of culture. The
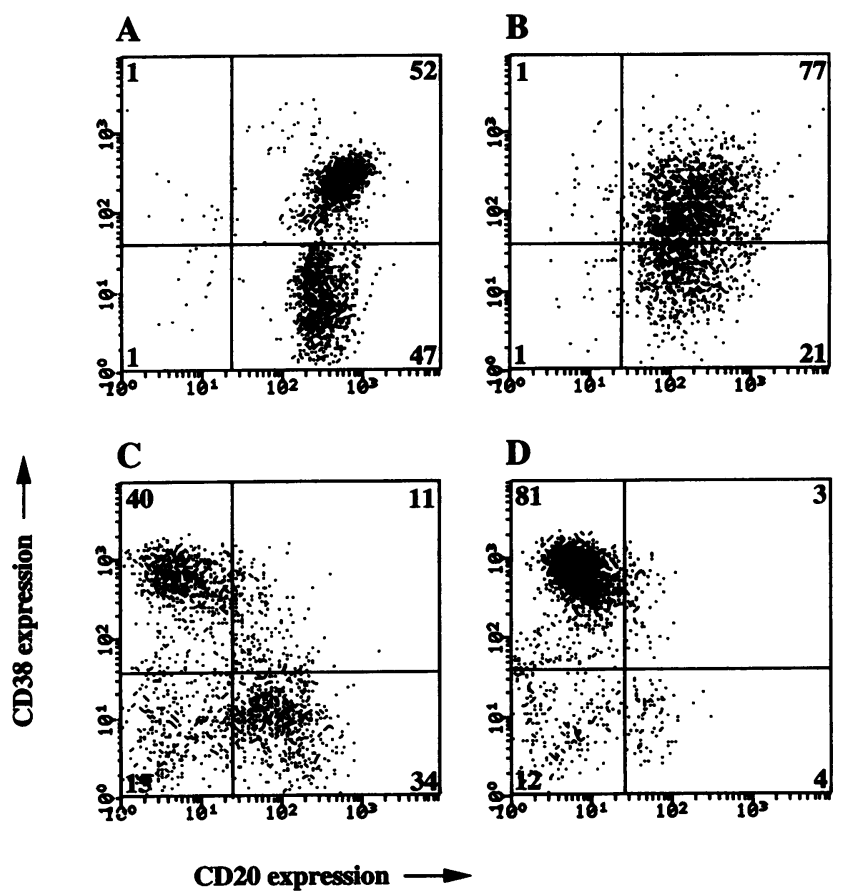

Figure 6. B cells cultured over synoviocytes lose their CD20 expression and acquire CD38 expression. Resting B cells were preactivated for 48 $h$ with SAC (SAC Blasts), and recultured on synoviocytes with IL-2 and IL-10 for 7 or 14 additional days. At each step of the culture, cells were washed and stained with FITC-conjugated anti-CD20 and phycoerythrin-conjugated anti-CD38 mAbs: $(A)$ freshly isolated tonsillar $B$ cells, $(B)$ SAC blasts, $(C)$ SAC blasts cocultured with synoviocytes for $7 \mathrm{~d}$, (D) SAC blasts cocultured with synoviocytes for 14 days. Fluorescence was analyzed by flow cytometry. Vertical and horizontal solid lines indicates the threshold of positive and negative immunofluorescence stainings. The percentages of cells in each quadrant are indicated. 
CD3

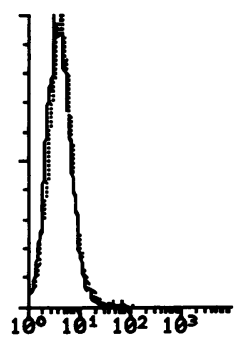

CD44

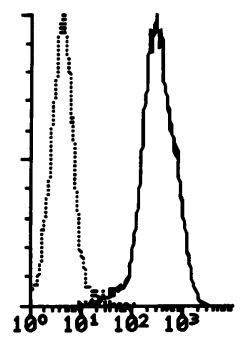

CD19
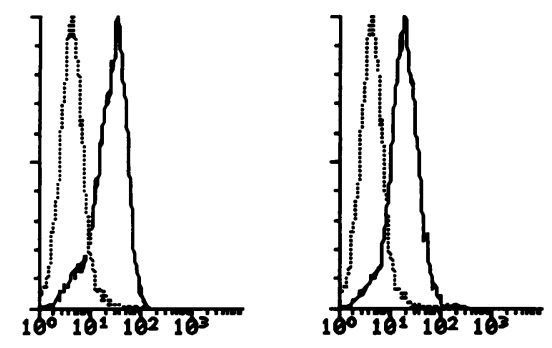

Figure 7. Phenotype of plasma cells generated in cocultures with synoviocytes. SAC blasts were cocultured with synoviocytes, IL-2 and IL-10 for $14 \mathrm{~d}$. Cells were harvested, washed and stained with FITC-conjugated anti-CD3, CD19, CD40, CD44, CD10, and CD28 mAbs. Horizontal and vertical axes illustrate log of fluorescence and relative cell numbers, respectively. Histogram corresponding to each mAb (solid line) are superimposed with that of the negative control (dashed line) performed with an isotype-matched unrelated $\mathrm{mAb}$.

decrease of viable cells was slower when B cells were cultured on MRC5 when compared with plastic, but cell survival was still low after $12 \mathrm{~d}$. In contrast, following an initial decrease of viable cells, B cell number cultured over synoviocytes remained stable between days 6 and 12, and the overall number of viable cells obtained after $12 \mathrm{~d}$ was close to the initial quantity of seeded cells. It is however important to note that proliferation of B cells was poor. Thus, the difference in the IgG inducing activity (measured in parallel in Fig. $8 \mathrm{~B}$ ) between synoviocytes, MRC5 cells and plastic appears to be related to a different ability to support B cell survival. Furthermore, the production of IgG per cell between days 9 and 12 was 4.6-fold higher on synoviocytes (0.19 ng/cell per day,) than on MRC5 (0.04 ng/ cell per day).

To confirm these results, the expression of CD38 and CD20 was compared between $B$ cells cocultured with synoviocytes or with MRC5. As presented in Fig. 9, $A$ and $B$, when SAC Blasts were cocultured over MRC5 with IL-2 and IL-10 the population of $\mathrm{CD} 20^{-} \mathrm{CD} 38^{\text {high }}$ cells represented only $19 \%$ of total cells, whereas it reached $53 \%$ in cocultures over synoviocytes. Moreover, Fig. $9 C$ clearly shows that CD38 expression was stronger on B cells cultured with synoviocytes (mean fluorescence intensity of CD38 staining: 508 over synoviocytes vs. 92 over MRC5). Therefore, synoviocytes in association with IL-2 and IL-10 are able to promote the survival of activated B cells as well as to support their terminal differentiation into non proliferative high rate IgG-secreting plasma cells.

\section{Discussion}

Plasma cells in rheumatoid synovium spontaneously secrete high amounts of Igs, with more IgG than IgM, as demonstrated
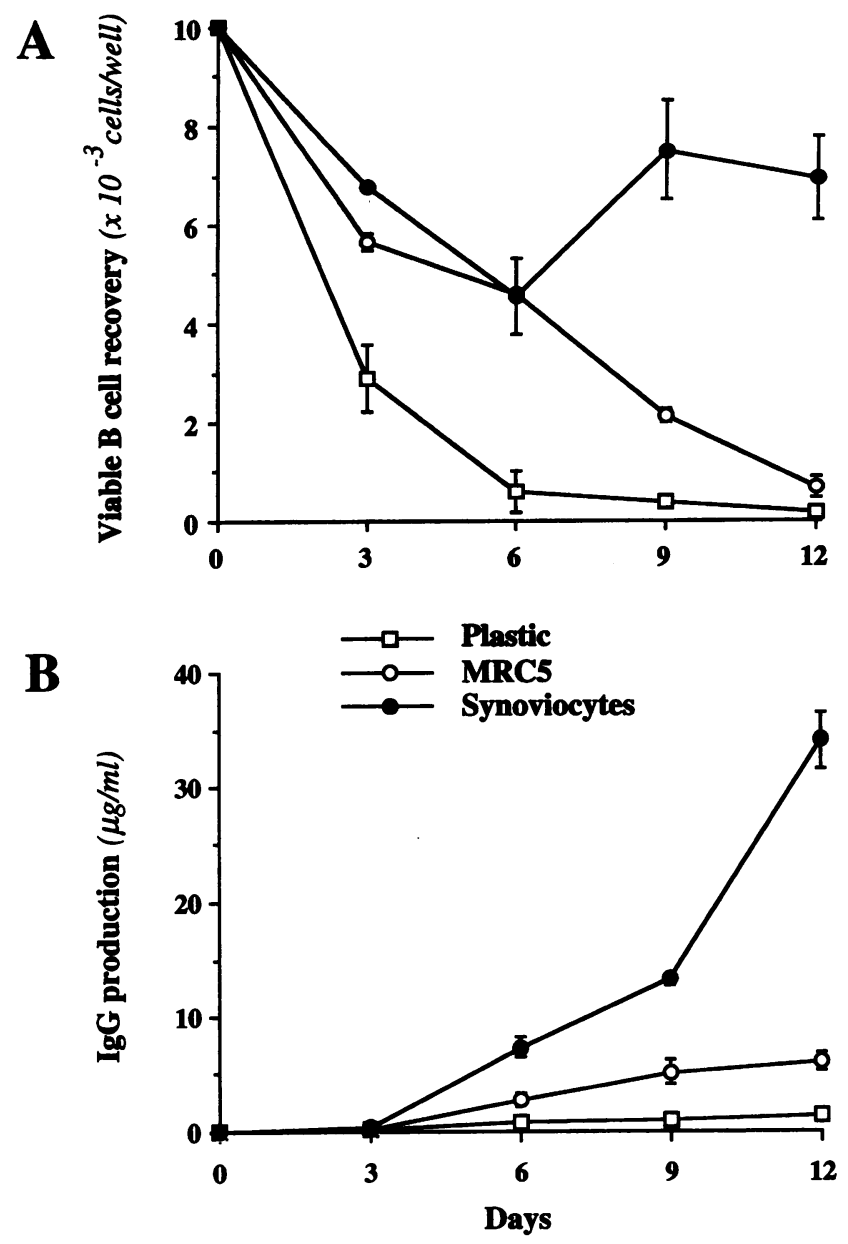

Figure 8. Synoviocytes promote B cell survival without important proliferation. $1 \times 10^{4} \mathrm{SAC}$ Blasts were cultured on plastic, or over a confluent monolayer of irradiated synoviocytes or MRC5. Cultures were performed in the presence of IL-2 $(10 \mathrm{ng} / \mathrm{ml})$ and IL-10 $(50 \mathrm{ng} / \mathrm{ml})$. $(A)$ Viable $B$ cell recovery was determined by trypan blue dye exclusion; synoviocytes were distinguished from B cells by their larger size. $(B)$ Supernatants were assayed in the IgG ELISA every third day. Results are expressed as mean $\pm S D$ of culture triplicates. Representative of three experiments.

by ex vivo cultures of rheumatoid synovial tissue $(9,19)$. The present study, which aimed at understanding the mechanisms of plasma cell accumulation in RA, has shown that resting B cells can be induced to spontaneously produce microgram amounts of Igs when cultured over a confluent monolayer of rheumatoid synoviocytes. Moreover, B cells activated through their antigen receptor with SAC particles produce hundreds of micrograms of IgG when cultured over synoviocytes in the presence of IL-2 and IL-10. These conditions allowed the generation of a population of cells bearing a typical plasma cell morphology, expressing high levels of intracytoplasmic Igs and surface CD38 and CD44, displaying CD40 and CD19, but lacking CD20 and CD10. This phenotype is similar to that of CD38 highly expressing plasma cells directly isolated from tonsils or bone marrow $(16,20)$. The phenotype of these cells is different from tumoral plasma cells such as plasmacytoma cell lines which express CD28 (18), or bone marrow cells from myeloma patients which lack surface CD19 (16).

These culture conditions indicate that IL-10 represents a key 

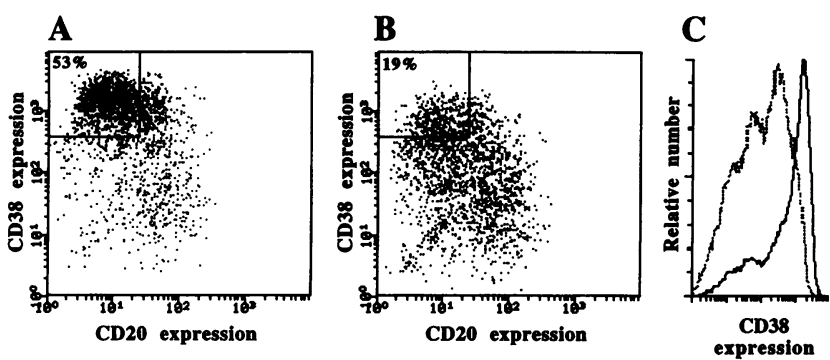

Figure 9. B cell CD38 expression is stronger when cocultures are performed with synoviocytes than with MRC5. SAC Blasts were cultured with IL-2 and IL-10 over a confluent monolayer of synoviocytes or MRC5. After $7 \mathrm{~d}$ of coculture, cells were stained with FITC-conjugated anti-CD20 and phycoerythrin-conjugated anti-CD38 antibodies. $(A) \mathrm{B}$ cells cultured over synoviocytes. $(B)$ B cells cultured over MRC5. Upper left square delineates negative expression of CD20 and high expression of CD38. (C) Expression of CD38 by B cells cultured with synoviocytes (solid line) or MRC5 (dashed line).

element in the induction of B cell differentiation. The important synergy between IL-2 and IL-10 in the cocultures has recently been described on CD40-activated B cells, and is best explained by the property of IL-10 to upregulate IL- 2 receptors (21). The other cytokines tested in the cocultures were unable to induce Ig production, including IL-6 which has been widely described as an important factor of B cell differentiation. Yet it is not excluded that IL- 6 may play a role in the B cell differentiation observed in the present cocultures, as their supernatants contain high levels of IL-6 (data not shown) which may come from both activated B cells (22) and synoviocytes (23). However, anti-GP-130 antibodies blocking the binding of IL-6 to its receptor (24) were unable to inhibit the Ig secretion observed in this culture system (data not shown).

B cells cocultured over synoviocytes with IL-2 and IL-10 proliferate relatively little as demonstrated by viable $B$ cell counting. When B cells were preactivated with SAC, never more than $75 \%$ of the initially seeded cells were recovered during the $12 \mathrm{~d}$ of coculture. It is likely that the cells obtained at the end of the culture do not represent the progeny of every $B$ cell of the initial population. Indeed, the observed decrease of cell number during the first $6 \mathrm{~d}$ of culture, followed by a second step of cell survival stability is suggestive of a selective process inducing the growth of a subpopulation of B cells. In fact, the detection of all Ig isotypes (IgA, IgM, and mainly IgG) in coculture supernatants suggests that the differentiating cells may be the population of B lymphocytes committed in vivo, and represented by the $\mathrm{IgD}^{-}$population in tonsil (25). Experiments with purified populations of tonsil B cells will permit to address this issue.

The coculture system was very efficient to induce terminal differentiation of resting tonsillar B cells, since $\sim 80 \%$ of the cells after 2 wk of coculture were mature plasma cells. These cells were able to produce around $0.2 \mathrm{ng} / \mathrm{cell}$ per day of IgG, an order of magnitude similar as previously estimated for bone marrow plasma cells cultured without particular care (26). In our hands, this coculture system was more potent to generate plasma cells than triggering of B cell CD40 in the presence of IL-2 and IL-10 (21), or culturing B cells with anti-CD3 activated $\mathrm{T}$ cell clone $(27,28)$, which had so far been described as the most efficient conditions allowing $B$ cell differentiation. It is also important to note that, unlike these two culture systems, the cocultures over synoviocytes suggest that differentiation of B cells can be induced in vitro in a CD40 independent fashion, since synoviocytes do not express surface GP-39, the ligand for CD40 (our unpublished results). This observation is in accordance with the increased production of IgM by patients with $\mathrm{X}$ linked Hyper-IgM syndrome, while their CD40-CD40-ligand interactions are abolished through point mutations in the CD40ligand gene (29-31).

Several other adherent fibroblast-like human cell lines were much less potent than synoviocytes to improve B cell differentiation. This particular property of synoviocytes to sustain the maturation of B cells into plasma cells was related to their ability to support B cell survival. Moreover, synoviocytes induced a more efficient differentiation of $B$ cells since the levels of IgG produced per cell were 4.6-fold higher, and their CD38 expression was stronger, in cocultures performed with synoviocytes than with MRC5. It is difficult to precisely define the role of synoviocytes in the B cell terminal differentiation process, but it is clear that contact with synoviocytes cannot circumvent need for B cell activation signals and cytokines such as IL-2 and IL-10. Preliminary results of two chamber culture systems, where B cells and synoviocytes were separated by a semi-permeable membrane, suggest that both direct cell contact and soluble factors are necessary for the differentiation to occur. Although interaction between $\alpha 4 \beta 1$ integrin (also known as VLA-4) and Fibronectin has been shown earlier to play an important role in terminal B cell differentiation of total human bone marrow cells (32), blocking anti-VLA-4 antibodies did not modify Ig production in cocultures of B cells with synoviocytes (data not shown). Further studies are now in progress to produce mouse monoclonal antibodies directed against synoviocyte membrane antigens, in order to further identify the molecules involved in the support of B cell differentiation into plasma cells through synoviocyte interaction.

The ability of synoviocytes to induce B cell differentiation was not related to their rheumatoid origin as normal synoviocytes possessed the same capacity. Since there is no plasma cells in normal synovium, these results lead to assume that the peculiar property of synoviocytes to induce terminal differentiation of B cells, is a necessary but not sufficient condition for plasma cells to accumulate in synovial membrane. The following events, which take place in rheumatoid but not in normal synovium, are most likely required for plasma cell accumulation. (a) An initial immune response to a presently unknown antigen; $(b)$ the infiltration of RA synovium by B cell-containing mononuclear cells; $(c)$ the local production of IL-10 by infiltrating monocytes and T cells (33); (d) the local production of $\mathrm{IL}^{2}$ 2 by infiltrating $\mathrm{T}$ cells (34); and (e) the intense proliferation of synoviocytes which may increase their interaction with B cells. Previous electron microscopic studies of rheumatoid synovium had demonstrated the close contact between plasma cells, macrophage-like cells, blastic $\mathrm{T}$ cells, and synoviocytes $(11,35)$, which suggest cell surface molecule or cytokine interactions between all these cell types. Besides, several studies indicate that RA synovial tissue is a privileged site for specific $B$ cell maturation. Analysis of synovial $V k$ transcripts has evidenced an oligoclonal expansion of B cells in a RA synovium, but neither in the PBL of the patient, nor in the spleen or PBL of normal individuals (36). Moreover, studies of RA synovial IgG rheumatoid factors have also revealed somatic mutations characteristic of an antigen-driven immune response $(37,38)$.

Thus, the remarkable ability of synoviocytes to support B cell differentiation, as well as the presence of monocytes/macro- 
phages secreting IL-10 and activated T cells producing IL-2, are likely to explain the accumulation and survival of plasma cells in rheumatoid synovium. It remains however an outstanding challenge to determine whether the synovial plasma cells were generated in the synovium from immigrating resting B cells or plasmablasts, and which are the specific molecules, expressed by synoviocytes, involved in their terminal differentiation into plasma cells.

\section{Acknowledgments}

We thank Professor J. Béjui, Dr. G. Herzberg, and Professor J. J. Comtet (HEH, Lyon, France) for providing synovium samples; Dr. S. SanchezMadrid (Seccion de Inmunologia, Hospital de la Princesa, Madrid, Spain) for providing anti-VLA-4 mAbs; Dr. T. Kishimoto (Osaka University Medical School, Osaka, Japan) for providing anti-GP-130 antibodies; Drs. F. Brière and Y. J. Liu for helpful discussions; and N. Courbière and M. Vatan for excellent secretarial assistance.

J. Dechanet and P. Merville are the recipients of a grant from the Fondation Mérieux (Lyon, France).

\section{References}

1. Liu, Y.-J., G. D. Johnson, J. Gordon, and I. C. M. MacLennan. 1992. Germinal centres in T-cell-dependent antibody responses. Immunol. Today. 13:17-21.

2. Banchereau, J., and F. Rousset. 1992. Human B lymphocytes: phenotype, proliferation and differentiation. Adv. Immunol. 52:125-251.

3. Clark, E. A., and J. A. Ledbetter. 1994. How B and T cells talk to each other. Nature (Lond.). 367:425-428.

4. Koch, G., D. G. Osmond, M. H. Julius, and R. Benner. 1981. The mechanism of thymus-dependent antibody formation in bone marrow. J. Immunol. 126:1447-1451.

5. Dilosa, R. M., K. Maeda, A. Masuda, A. K. Szakal, and J. G. Tew. 1991. Germinal center B cells and antibody production in the bone marrow. J. Immunol. 146:4071-4077.

6. Kobayashi, I., and M. Ziff. 1973. Electron microscopic studies of lymphoid cells in the rheumatoid synovial membrane. Arthritis Rheum. 16:471-486.

7. Harris, E. D., Jr. 1990. Rheumatoid arthritis: pathophysiology and implications for therapy. N. Engl. J. Med. 322:1277-1289.

8. Natvig, J. B., I. Randen, K. Thompson, O. Forre, and E. Munthe. 1989. The B cell system in the rheumatoid inflammation. New Insights into the pathogenesis of rheumatoid arthritis using synovial B cell hybridoma clones. Springer Semin. Immunopathol. 11:301-313.

9. Smiley, J. D., C. Sachs, and M. Ziff. 1968. In vitro synthesis of immunoglobulin by rheumatoid synovial membrane. J. Clin. Invest. 47:624-632.

10. Bankhurst, A. D., G. Husby, and R. C. Williams. 1976. Predominance of $\mathrm{T}$ cells in the lymphocytic infiltrates of synovial tissues in rheumatoid arthritis. J. Clin. Invest. 47:624-632.

11. Kurosaka, M., and M. Ziff. 1983. Immunoelectron microscopic study of the distribution of T cell subsets in rheumatoid synovium. J. Exp. Med. 158:11911210.

12. Dechanet, J., J. Briolay, M.-C. Rissoan, P. Chomarat, J.-P. Galizzi, J. Banchereau, and P. Miossec. 1993. Interleukin 4 inhibits growth factor-stimulated rheumatoid synoviocyte proliferation by blocking the early phases of the cell cycle. J. Immunol. 151:4908-4917.

13. Vallé, A., C. E. Zuber, T. Defrance, O. Djossou, M. De Rie, and J. Banchereau. 1989. Activation of human B lymphocytes through CD40 and interleukin 4. Eur. J. Immunol. 19:1463-1467.

14. Defrance, T., B. Vanbervliet, J. P. Aubry, and J. Banchereau. 1988. Interleukin 4 inhibits the proliferation but not the differentiation of activated human B cells in response to interleukin 2. J. Exp. Med. 168:1321-1337.

15. Defrance, T., J. P. Aubry, F. Rousset, B. Vanbervliet, J. Y. Bonnefoy, N. Arai, Y. Takebe, T. Yokota, F. Lee, K. Arai, J. E. de Vries, and J. Banchereau. 1987. Human recombinant interleukin 4 induces Fcg receptors (CD23) on normal human B lymphocytes. J. Exp. Med. 165:1459-1467.

16. Harada, H., M. M. Kawano, N. Huang, Y. Harada, K. Iwato, O. Tanabe, H. Tanaka, A. Sakai, and A. Kuramoto. 1993. Phenotypic difference of normal plasma cells from mature myeloma cells. Blood. 81:2658-2663.

17. Ling, N. R., I. C. M. MacLennan, and D. Mason. 1987. B-cell and plasma cell antigens: new and previously defined clusters. In Leucocyte Typing III. A. J. McMichael, editor. Oxford University Press, Oxford. 302-335.

18. Kozbor, D., A. Moretta, H. A. Messner, L. Moretta, and C. M. Croce. 1987. Tp44 molecules involved in antigen-independent $\mathrm{T}$ cell activation are expressed on human plasma cells. J. Immunol. 138:4128-4132.

19. Miossec, P., J. Briolay, J. Dechanet, J. Wijdenes, H. Martinez-Valdez, and J. Banchereau. 1992. Inhibition of the production of proinflammatory cytokines and immunoglobulins by interleukin-4 in an ex vivo model of rheumatoid synovitis. Arthritis Rheum. 35:874-883.

20. Brieva, J. A., E. Roldan, C. Rodriguez, and G. Navas. 1994. Human tonsil, blood and bone marrow in vivo-induced B cells capable of spontaneous and high-rate immunoglobulin secretion in vitro: differences in the requirements for factors and for adherent and bone marrow stromal cells, as well as distinctive adhesion molecule expression. Eur. J. Immunol. 24:362-366.

21. Fluckiger, A.-C., P. Garrone, I. Durand, J. P. Galizzi, and J. Banchereau. 1993. IL-10 upregulates functional high affinity IL-2 receptors on normal and leukemic B lymphocytes. J. Exp. Med. 178:1473-1481.

22. Freeman, G. J., A. S. Freedman, S. N. Rabinowe, J. M. Segil, J. Horowitz, and K. Rosen. 1989. Interleukin 6 gene expression in normal and neoplastic B cells. J. Clin. Invest. 83:1512-1518.

23. Guerne, P.-A., B. L. Zuraw, J. H. Vaughan, D. A. Carson, and M. Lotz. 1989. Synovium as a source of interleukin 6 in vitro: contribution to local and systemic manifestations of arthritis. J. Clin. Invest. 83:585-592.

24. Taga, T., M. Narazaki, K. Yasukawa, T. Saito, D. Miki, M. Hamaguchi, S. Davis, M. Shoyab, G. D. Yancopoulos, and T. Kishimoto. 1992. Functional inhibition of hematopoietic and neurotrophic cytokines by blocking the interleukin 6 signal transducer gp130. Proc. Natl. Acad. Sci. USA. 89:10998-11001.

25. Defrance, T., B. Vanbervliet, F. Brière, I. Durand, F. Rousset, and J. Banchereau. 1992. Interleukin 10 and transforming growth factor $\beta$ cooperate to induce anti-CD40-activated naive human B cells to secrete Immunoglobulin A. J. Exp. Med. 175:671-682.

26. Hibi, T., and H.-M. Dosch. 1986. Limiting dilution analysis of the B cell compartment in human bone marrow. Eur. J. Immunol. 16:139-145.

27. Vernino, L. A., L. M. McAnally, J. Ramberg, and P. E. Lipsky. 1992. Generation of nondividing high rate Ig-secreting plasma cells in cultures of human B cells stimulated with anti-CD3-activated T cells. J. Immunol. 148:404-410.

28. Blanchard, D., C. Gaillard, P. Hermann, and J. Banchereau. 1994. Role of CD40 antigen and interleukin-2 in T cell dependent human B lymphocyte growth. Eur. J. Immunol. 24:330-335.

29. Aruffo, A., M. Farrington, D. Hollenbaugh, X. Li, A. Milatovich, S. Nonoyama, J. Bajorath, L. S. Grosmaire, R. Stenkamp, M. Neubauer, R. L. Roberts, R. J. Noelle, J. A. Ledbetter, U. Francke, and H. D. Ochs. 1993. The CD40 ligand, gp39, is defective in activated T cells from patients with X-linked hyper-IgM syndrome. Cell. 72:291-300.

30. Allen, R. C., R. J. Armitage, M. E. Conley, H. Rosenblatt, N. A. Jenkins, N. G. Copeland, M. A. Bedell, S. Edelhoff, C. M. Disteche, D. K. Simoneaux, W. C. Fanslow, J. Belmont, and M. K. Spriggs. 1993. CD40 ligand gene defects responsible for X-linked hyper-IgM syndrome. Science (Wash. DC). 259:990993.

31. Korthäuer, U., D. Graf, H. W. Mages, F. Brière, M. Padayachee, S. Malcolm, A. G. Ugazio, L. D. Notarangelo, R. J. Levinsky, and R. A. Kroczek. 1993. Defective expression of T-cell CD40 ligand causes X-linked immunodeficiency with hyper-IgM. Nature (Lond.). 361:539-541.

32. Roldan, E., A. Garcia-Pardo, and J. A. Brieva. 1992. VLA-4-fibronectin interaction is required for the terminal differentiation of human bone marrow cells capable of spontaneous and high rate immunoglobulin secretion. J. Exp. Med. 175:1739-1747.

33. Katsikis, P. D., C.-Q. Chu, F. M. Brennan, R. N. Maini, and M. Feldmann. 1994. Immunoregulatory role of interleukin 10 in rheumatoid arthritis. J. Exp. Med. 179:1517-1527.

34. Lipsky, P. E., L. S. Davis, J. J. Cush, and N. Oppenheimer-Marks. 1989 The role of cytokines in the pathogenesis of rheumatoid arthritis. Springer Semin. Immunopathol. 11:123-162.

35. Iguchi, T., and M. Ziff. 1986. Electron microscopic study of rheumatoid synovial vasculature. J. Clin. Invest. 77:355-361.

36. Lee, S.-K., S. L. Bridges, P. M. Kirkham, W. J. Koopman, and J. Schroeder H.W. 1994. Evidence of antigen receptor-influenced oligoclonal B lymphocyte expansion in the synovium of a patient with longstanding rheumatoid arthritis. $J$. Clin. Invest. 93:361-370.

37. Olee, T., E. W. Lu, D.-F. Huang, R. W. Soto-Gil, M. Deftos, F. Kozin, D. A. Carson, and P. P. Chen. 1992. Genetic analysis of self-associating immunoglobulin $\mathrm{G}$ rheumatoid factors from two rheumatoid synovia implicates an antigendriven response. J. Exp. Med. 175:831-842.

38. Randen, I., V. Pascual, K. Victor, K. M. Thompson, O. Forre, J. D. Capra and J. B. Natvig. 1993. Synovial IgG rheumatoid factors show evidence of an antigen-driven immune response and a shift in the $\mathrm{V}$ gene repertoire compared to IgM rheumatoid factors. Eur. J. Immunol. 23:1220-1225. 